See discussions, stats, and author profiles for this publication at: https://www.researchgate.net/publication/309273576

\title{
Monitoring of surface movement in a large area of the open pit iron mines (Carajás, Brazil) based on A-DInSAR techniques using TerraSAR-X data
}

Conference Paper · October 2016

DOI: $10.1117 / 12.2242064$

CITATIONS

0

4 authors:

José Claudio Mura

National Institute for Space Research, Brazil

103 PUBLICATIONS 854 CITATIONS

SEE PROFILE

Fábio Furlan Gama

National Institute for Space Research, Brazil

59 PUBLICATIONS 511 CITATIONS

SEE PROFILE
READS

52

Waldir Renato Paradella

National Institute for Space Research, Brazil

202 PUBLICATIONS 1,181 CITATIONS

SEE PROFILE

Guilherme G. Silva

National Institute for Space Research, Brazil

16 PUbLiCATIONS 112 CITATIONS

SEE PROFILE

Some of the authors of this publication are also working on these related projects:

SAR Geoscience View project 


\title{
Monitoring of Surface Movement in a Large Area of the Open Pit Iron Mines (Carajás, Brazil) Based on A-DInSAR techniques using TerraSAR-X data.
}

\author{
José C. Mura, Waldir R. Paradella, Fabio F. Gama, Guilherme G. Silva \\ National Institute for Space Research (INPE), Earth Observation Department, \\ São José dos Campos, São Paulo, 1227-010 Brazil
}

\begin{abstract}
PSI (Persistent Scatterer Interferometry) analysis of large area is always a challenging task regarding the removal of the atmospheric phase component. This work presents an investigation of ground deformation measurements based on a combination of DInSAR Time-Series (DTS) and PSI techniques, applied in a large area of the open pit iron mines located in Carajás (Brazilian Amazon Region), aiming at detect high rates of linear and nonlinear ground deformation. These mines have presented a historical of instability and surface monitoring measurements over sectors of the mines (pit walls) have been carried out based on ground based radar and total station (prisms). By using a priori information regarding the topographic phase error and phase displacement model derived from DTS, temporal phase unwrapping in the PSI processing and the removal of the atmospheric phases can be performed more efficiently. The DTS results provided the first estimate of the topographic error and the phase displacement model for the PSI analysis. A set of 33 TerraSAR-X-1 images, acquired during the period from March 2012 to April 2013, was used to perform this investigation. The DTS analysis was carried out on a stack of multi-look unwrapped interferogram using an extension of the SVD to obtain the Least-Square solution. The height errors and deformation rates provided by the DTS approach were subtracted from the stack of interferogram to perform the PSI analysis. This procedure improved the capability of the PSI analysis to detect high rates of deformation as well as increased the numbers of point density of the final results. The proposed methodology showed good results for monitoring surface displacement in a large mining area, which is located in a rain forest environment, providing very useful information about the ground movement for planning and risks control.
\end{abstract}

Keywords: DInSAR time-series, PSI, surface deformation, TerraSAR-X, open pit iron mine, Amazon Region

\section{INTRODUCTION}

Taking advantage of multi-temporal SAR acquisitions the use of A-DinSAR techniques improves the capability to detect deformation phenomena. DTS technique have been proposed and used successfully. ${ }^{1-6}$ This technique using a small baseline (SBAS) subset ${ }^{7}$ has been applied by several authors. ${ }^{8-11}$ PSI approach ${ }^{12-15}$ based on a stack of differential interferograms, relies on identifying pixels whose scattering properties vary little with time and look angle, allowing a temporal analysis of the interferometric phase of individual point targets, and providing an accurate information related to the surface target displacements. PSI provides better accuracy than that of DTS technique. The former can better model and diminish the effect of the atmospheric phase, which is related to the path delay heterogeneity during the acquisitions times, whereas the latter can detect larger deformation rates and provides a more homogeneous and extensive information related to the ground deformation, but at the cost of a loss in spatial resolution.

This study presents an application of A-DInSAR techniques to monitor surface deformation in a large area of the open pit iron mines, located in Carajás Mineral Province (Brazilian Amazon region). In the next section a description of this particular mining area as well as some related ground deformation instabilities are presented. The combined approach based on DTS and PSI techniques using 33 StripMap TSX-1 scenes is presented in the section 3. The results of the combined techniques are presented in section 4. Finally, the potential and the results of this approach for monitoring ground movement in a large mining area are discussed. 


\section{STUDY AREA}

The most important Brazilian mineral province is located in the Amazon Region, Carajás-PA, encompassing 39 iron bodies with reserves of 18 billion tons, with an area of $120,000 \mathrm{Km}^{2}$. This province is marked by mountainous terrains, characterized by a set of hills and plateaus (altitudes from 500 to $900 \mathrm{~m}$ ) surrounded by southern and northern lowlands (altitudes around $200 \mathrm{~m}$ ), deep chemical weathering which produces thick oxisols (latosols), totally covered by Ombrophilous Equatorial forest communities with complex and multilevel canopies and numerous species. ${ }^{16}$

The iron deposits are covered by thick, hard iron-crust (lateritic duricrusts) developed over volcanic rocks and ironstones. Specific low-density savanna-type vegetation (campus rupestres) is associated with the deposits, and shows a strong contrast (clearing) with the dense equatorial forest. Fully owned by Vale S.A. mining company, the exploration in Carajás is carried out through state of the art open pit benching. The current mining activities are related to two iron orebodies (N4 and N5) and were started by 1984 with the N4E mine and the N5W mine in 1998. Carajás Mining Complex (N4 and N5 bodies) (Figure 1) produces approximately 300,000 metric tons of iron ore per day. ${ }^{17}$

Surface instabilities can be expected at any mining activity. Open pit operations usually have significant areas of extent and can also influence large portions of terrain adjacent to the pit crest. Rock mass movements and surface deformations potentially lead to slope instabilities or wall failures due to regular open pit mining operations. This scenario in Carajás gets worse over time due to intense deep excavations in saprolitic soil and rock masses of very low geomechanical quality, coupled with blasting practices and heavy precipitation of the moist tropics, with deleterious effects on the overall stability. Vale's geotechnical team has monitored the presence of fractures on bench walls, tension cracks on berms and road ramps, through visual inspection, total station/reflecting prisms measurements and ground based radar.

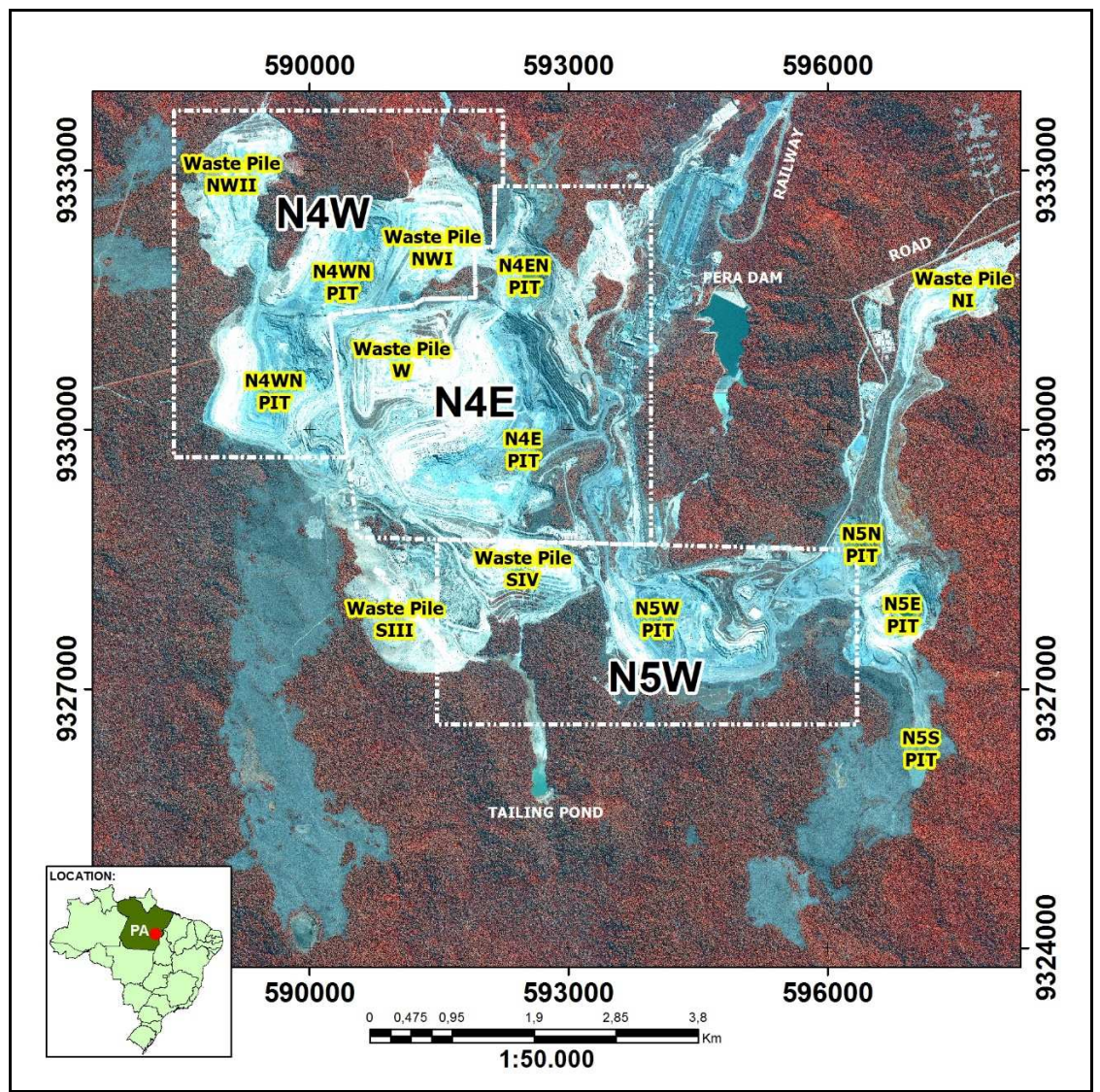

Figure 1. Location of Carajás iron complex in the Brazilian Amazon region (Pará State), showing the open pits, waste piles and related mining infrastructures. 


\section{METHODOLOGY}

The proposed approach described in this paper is shown in Figure 2, where the combination of two techniques, DTS and PSI, are used in order to improve the capability of the PSI technique to detect nonlinear deformation, removal of the orbit phase trend error, removal of the atmospheric phase delay in large area, as well as increase the numbers of point density of the final results. The deformation model and the DEM errors estimated by the DTS are subtracted from the master referenced differential interferogram and the residual phases are processed with PSI technique. This approach was already applied to detect nonlinear deformation in a small area of the Carajás Mineral Province. ${ }^{18}$. In this work we focus on the removal of the atmospheric phase component in large area, where it is expected that it is not constant over the area.

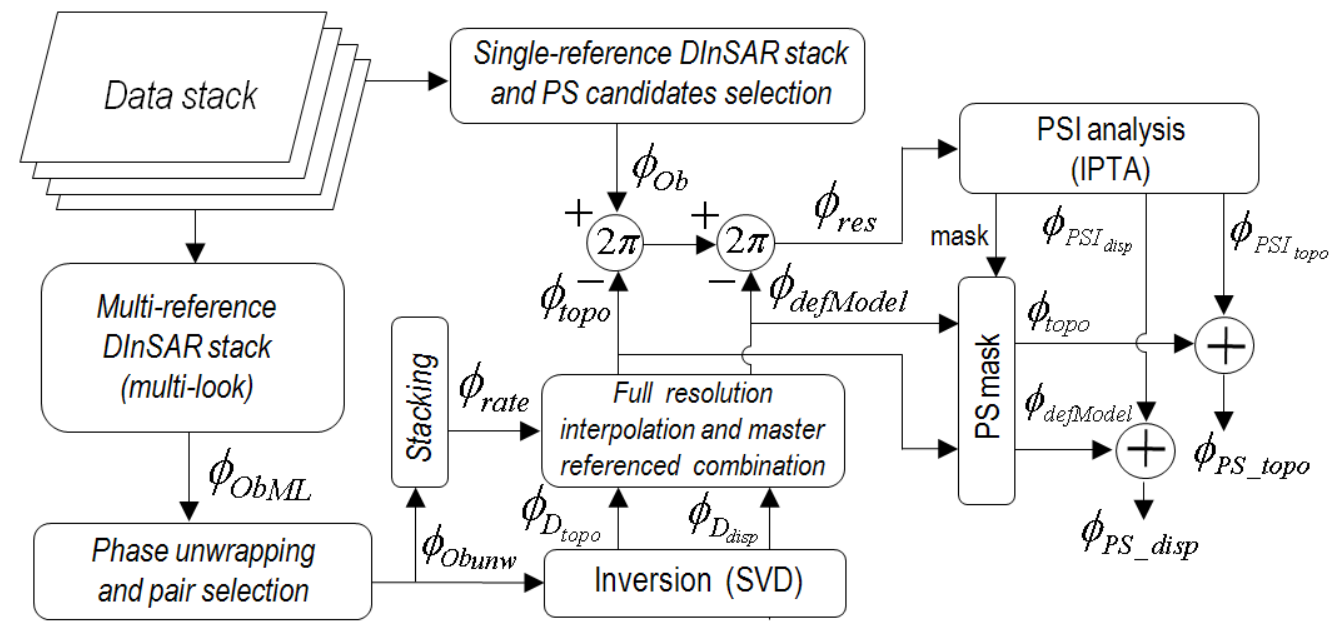

Figure 2. Block diagram of the proposed approach

\subsection{DTS technique}

The use of standard Differential SAR Interferometry (DInSAR) technique for monitoring surface deformation has been applied since the early 90s. DInSAR technique aims to measure deformation on the ground using a pair of SAR images acquired at different times and different position of the satellite between the two acquisitions. The interferogram generated from these two co-registrated images has phase's components contributions from the topography, deformations, atmosphere and noise. By knowing the positions of the satellite and the surface topography it is possible to subtract the topographic phase component and to measure the deformation. Performing this previous proceeding what remains in the differential interferogram is a contribution due to the ground displacement between acquisitions added with other undesirable component, represented by:

$$
\phi_{\Delta t}=\phi_{d e f}+\phi_{h}+\phi_{a t m}+\phi_{\beta}+\phi_{\eta}
$$

where $\phi_{d e f}$ is the phase change due to the displacement of the pixel in the satellite line-of-sight (LoS) direction, $\phi_{h}$ is the topographic phase error, $\phi_{a t m}$ is the atmospheric phase delay, $\phi_{\beta}$ is the residual phase due to orbit errors and $\phi_{\eta}$ is the phase noise.

The ambiguity of $2 \pi$ in the differential interferometric phase (fringes) makes it impossible to interpret this phase in terms of absolute range change. However, it is possible to estimate the relative range change between points within a differential interferogram, by integrating the number of fringes between them, using a process known as phase unwrapping. ${ }^{19}$ Ground deformation monitoring is suitable when the $\phi$ def exceeds the other four phase components represented in the equation (1), for this reason the use of a precise DEM is desirable to compensate part of the topographic phase error; a spatial filtering (multi-look) can reduce the phase noise, however the atmospheric phase delay and the residual phase due to orbit errors cannot be filtered out or estimated, respectively. 
Taking advantage of multi-temporal SAR acquisitions the use of A-DinSAR techniques has improved the capability to detect deformation phenomena. DTS and PSI algorithms have been developed do better address the standard DInSAR limitations, by using a redundant number of differential interferograms with potential to determine spatially and temporally ground displacement, where the desirable deformation information can be separated from topography error, atmospheric delay and noise.

Considering a set of $\mathrm{M}$ differential interferograms generated from a set of $\mathrm{N}+1$ SAR images acquired at the ordered time $\left(t_{0}, t_{1}, \ldots, t_{N}\right)$, where each differential interferometric pair is constructed in a given time interval $(\Delta t)$, as represented in equation (1), following the rule of small time interval between acquisitions or small baseline subset (SBAS). ${ }^{7}$ The observed multi-look unwrapped phase values of this point in relation to the reference point may be organized in a vector of $\mathrm{M}$ elements, represented by the equation (2).

$$
\phi_{M L O b}^{T}=\left[\phi_{\Delta t 1}, \phi_{\Delta t 2}, \ldots, \phi_{\Delta t M}\right]
$$

Being $\mathrm{N}$ the number of unknown phase values related to the range displacement of the selected point at the ordered time $\left(t_{1}, t_{2}, \ldots, t_{N}\right)$, considering $t_{0}$ as a reference epoch (zero deformation), the displacement vector can be represented by the equation (3).

$$
\phi_{\text {disp }}^{T}=\left[\phi_{\Delta r 1}\left(t_{1}\right), \phi_{\Delta r 2}\left(t_{2}\right), \ldots, \phi_{\Delta r N}\left(t_{N}\right)\right]
$$

The relation between range displacement (3) and the observed data (2) can be represented as one system of $\mathrm{M}$ equation and $\mathrm{N}$ unknown variables in the matrix form in equation (4), where $\mathrm{A}$ is a $\mathrm{M}$ by $\mathrm{N}$ matrix of the operators $(+1,-1,0)$ between the unwrapped interferometric pairs.

$$
A \phi_{\text {disp }}=\phi_{M L O b}
$$

The solution of equation (4) can be obtained in the Least Squares (LS) sense ${ }^{2}$. A physically sound solution can be found in terms of mean phase velocity among time-adjacent acquisitions using the SVD decomposition ${ }^{7}$ and a final integration can be used to achieve the final solution $\phi$ Disp. The estimation of the topographic error ( $\phi$ Dtopo) can be determined by the coefficient of a linear regression that relates the topographic phase with the normal baselines that composes the $\mathrm{M}$ interferograms, based on the following relation,

$$
\left[\phi_{\partial h 1}, \phi_{\partial h 2}, \ldots, \phi_{\partial h M}\right]=\frac{4 \pi}{\lambda R \sin \theta}\left[B_{n 1}, B_{n 1}, \ldots, B_{n M}\right]
$$

where $\lambda$ is the wave length, $\mathrm{R}$ and $\theta$ are the slant range distance and incidence angle of the master image used to coregistrated the stack of images and $\mathrm{Bn}$ is the normal baseline.

In this study the inversion of the system of equation was performed by using an extension of the SVD with a set of additional weighted constrain on the acceleration of the displacement to control the smoothness of the time-series solutions. ${ }^{3}$ Temporal smoothing is enhanced using a finite difference approximation constraint, assuming less deformation to occur during short period of time. The smoothing constraint and the height error related term were incorporated into the inversion of the system that relates the observed unwrapped interferograms phase with the average displacement velocity. ${ }^{20}$ Details of this subject with an example of application in Carajás were already presented. ${ }^{21}$

A stack with 33 TSX-1 Strip Map scenes was used to perform the investigation. The Single Look Complex (SLC) images were acquired from March 2012 to April 2013 under ascending passes (look azimuth $~ 80^{\circ}$ ), incidence angle range of $39.89^{\circ}-42.21^{\circ}$, spatial resolution of $1.7 \mathrm{~m} \mathrm{x} 3.49 \mathrm{~m}$ (range $\mathrm{x}$ azimuth), pixel spacing of $1.36 \mathrm{x} 1.90 \mathrm{~m}(\mathrm{range} \times$ azimuth) and swath width of $30 \mathrm{~km}$. A GeoEye-1 stereo-pair images acquired on July 1, 2012 was used to produce a high-resolution digital elevation model (DEM) and orthoimages (panchromatic and multispectral), with spatial resolution of 2 meters in order to improve the differential interferometric processing. ${ }^{22}$

It was planned do have one image every 11 days but this sequence failed twice, creating discontinuities of 22 and 44 days. In order to cover the time span of acquisitions it was simulate the differential interferometric pairs for a time interval up to 45 days and a maximum perpendicular baseline up to 400 meters as shown in Figure 3 . Visual inspection was used to discard interferograms with compromising phase unwrapping errors. Most of the selected pairs belong to the shortest time interval among acquisitions (11 days). 


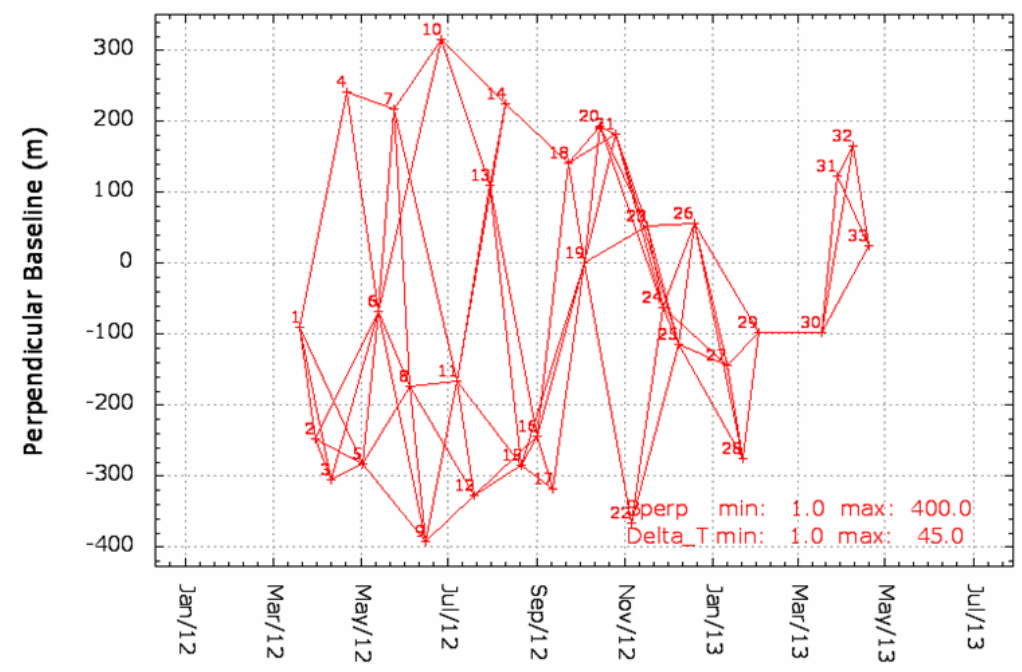

Figure 3. Interferometric pairs selected based on the stack of 33 TSX-1 images.

The results of the DTS, ground displacement ( $\phi$ Ddisp) and topographic error ( $\phi$ Dtopo), are resampled for full resolution, in order to have the same pixel spacing as that of the differential interferograms for the PSI analysis (Figure 2). An important transformation is performed to change the phase displacement ( $\phi$ Ddisp) to the PSI phase model, which is referenced to the master image, as used in the PSI analysis, represented by:

$$
\phi_{\text {Disp }}^{T}=\phi_{\text {Didel }}\left(t_{1}\right)-\phi_{\text {Disp }}\left(t_{M a}\right), \phi_{\text {Disp }}\left(t_{2}\right)-\phi_{\text {Disp }}\left(t_{M a}\right), \ldots, \phi_{D i s p}\left(t_{N}\right)-\phi_{\text {Disp }}\left(t_{M a}\right)
$$

The phase displacement model in the equation (9) incorporates the phase rate (linear deformation) and the nonlinear deformation in relation to a reference point, located in a stable area.

\subsection{PSI technique}

The Persistent Scatterer Interferometry technique (PSI) relies on identifying pixels whose scattering properties vary little with time and look angle in a stack of co-registrated SLC images. The idea of PSI is to analyze the temporal and spatial characteristics of the interferometric phase of individual point targets. These point targets are coherent even for the interferometric pairs with long spatial baselines and remain stable over long time periods to permit analysis of the phase history. $^{12-15}$

PSI analysis was carried out using the IPTA module (Gamma RS software). ${ }^{14}$ The IPTA processing sequence includes SAR SLC image co-registration to generate the stack of interferograms (the master scene was selected based on a configuration that has low perpendicular baseline dispersion and near to center of the image sequence), stack of differential interferograms generation, point target candidate determination (based on spectral phase diversity and low intensity variability). IPTA is based in two-dimensional regression (phase model indicates a linear dependence of the topographic phase on the perpendicular baseline and also indicates a linear time dependence for deformation rates) and model refinement (update the DEM, update deformation rates, baseline refinement).

For the PSI analysis, a stack of 33 co-registrated SLC images was used to generate the interferometric pairs in relation to a master image, whose selection was made based on low perpendicular baseline dispersion and nearly at the center of the time series, as shown in Figure 4. PS candidates are estimated based on the amplitude dispersion index and low spectral diversity at each pixel of the stack of the co-registrated images. Considering a reference point located in a stable area and a selected generic PS, the observed wrapped phase values of this point in relation to the reference point can be organized in a vector of $\mathrm{N}$ elements, as

$$
\phi_{O b}^{T}=\left[\phi_{\Delta t 1}, \phi_{\Delta t 2}, \ldots, \phi_{\Delta t N}\right]
$$




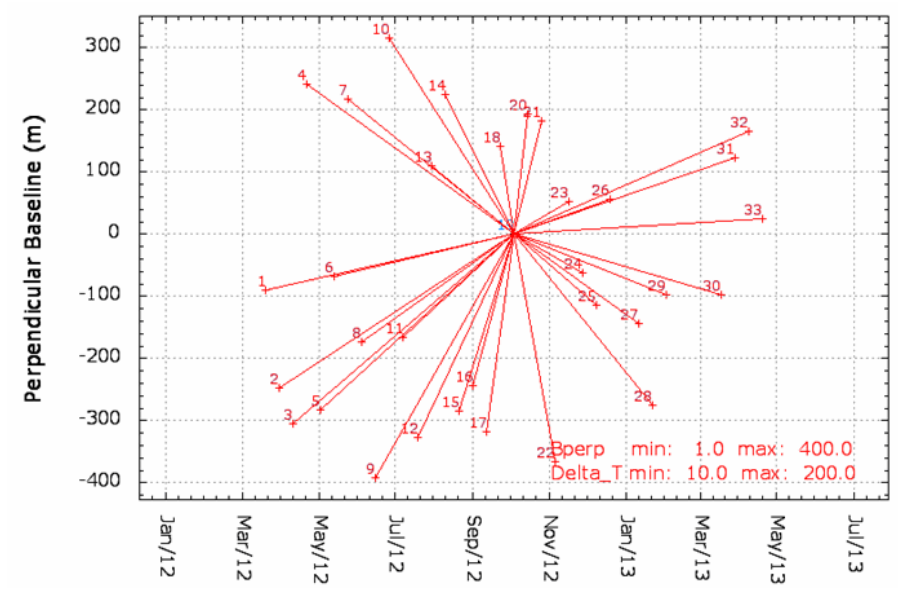

Figure 4. Interferometric pairs selected based on the master images (Oct. 04 2012).

The vector of wrapped phase represented in (10) has the components of deformation, topographic error, atmospheric artifacts, orbit errors, and noise. In this work we propose using a priori knowledge of some phase components to improve the performance of the PSI analysis.

The results obtained from the DTS analysis, the topographic error $\phi$ Dtopo, and the phase deformation model $\phi$ DispModel, represented by (9), are subtracted from the observed phase (10) in order to reduce the effects of these phase components, aiming at improving the PSI analysis. The phase $\phi D$ topo is subtracted (modulo- $2 \pi$ ) from the observed phase vector (10), resulting in the first residual wrapped phase, which is then subtracted (modulo- $2 \pi$ ) from the phase displacement model, as shown in Figure 2, resulting in a residual wrapped phase represented in the equation (11).

$$
\phi_{\text {res }}^{T}=\phi_{O b}^{T}-\phi_{\text {topo }}^{T}-\phi_{\text {Disp Model }}^{T}
$$

The residual phase represented in (11) presents the atmospheric phase component, the phase noise and the residual phase due to the errors occurred during the DTS processing in the estimation of the topographic error as well as errors related to the phase model in (9), which contain the components of the linear and nonlinear deformation. Considering that the larger phase components (topography error, high rate and nonlinear movement) have been removed in (11), the PSI processing can be better performed the removal of the atmospheric phase and noise, improving the determination of the final ground displacement.

Perform PSI analysis of large area is always a challenging task regarding the removal of the atmospheric phase component. An important aspect of IPTA technique is the possibility of a step-wise, iterative improvement for different parameters to estimate the topographic error, atmospheric phase delay and ground displacement. In this work it was performed three interactions in order to estimate and removal of the atmospheric phase. Atmospheric phase delay may account for most of the linear regression deviation (residues) related to the linear deformation. The residue layers can presents phase unwrapping errors, including path effect due to the local reference used. In order to overcome this problem the layers with phase unwrapping error are transformed to complex format, filtered spatially an afterwards unwrapped again until all layers have been unwrapped properly. This step can be repeated until find a suitable box size for the filter. Figure 5 shows an example of the three atmospheric phase components determined and removed in three interactions, for the interferometric pair composed by the imagens acquired on Oct 172012 and Oct 282012 . We can note from Figure 5 that the greatest disturbance in phase was found in the first interaction.

The final solution for the deformation was obtained by adding the PSI result to the DTS phase displacement model, represented by the equation (12), and for the final topographic error, by the addition of the components from PSI analysis with the DTS, as represented in equation (13). Only the PS present in the PS_mask were validated (Figure 2).

$$
\begin{aligned}
& \phi_{P S \_d i s p}^{T}=\phi_{\text {PSI disp }}^{T}+\phi_{\text {DispModel }}^{T} \\
& \phi_{P S \_t o p o}^{T}=\phi_{\text {PSI topo }}^{T}+\phi_{\text {Dtopo }}^{T} .
\end{aligned}
$$



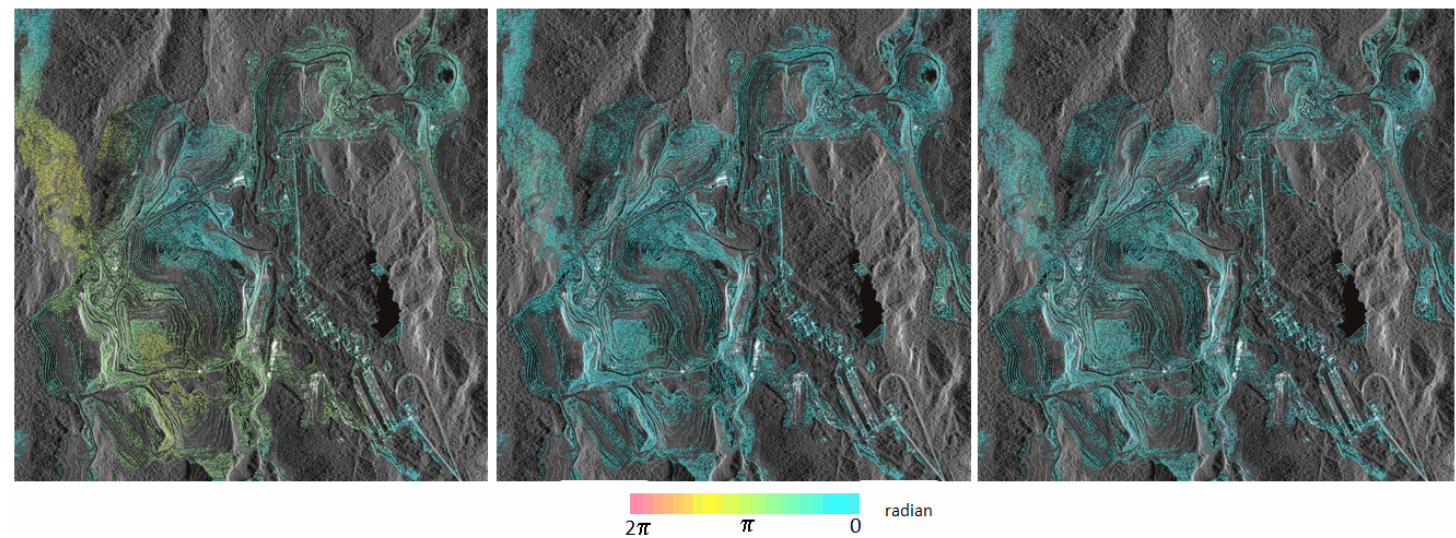

Figure 5. Example of atmospheric phase components obtained after three interactions for the pair of the images acquired on Oct 172012 and Oct 282012

\section{RESULTS AND DISCUSSION}

Ground displacement map obtained with the proposed methodology using 33 TSX-1 scenes, covering the time span from March 2012 to April 2013 (dry and wet seasons), is shown in Figure 6. PSI processing, using previous information about phase displacement model and DEM error derived from the DTS, allows detection of ground movement in a large area, covering the complex of the N4 and N5 open pit iron mines (Figure 1).

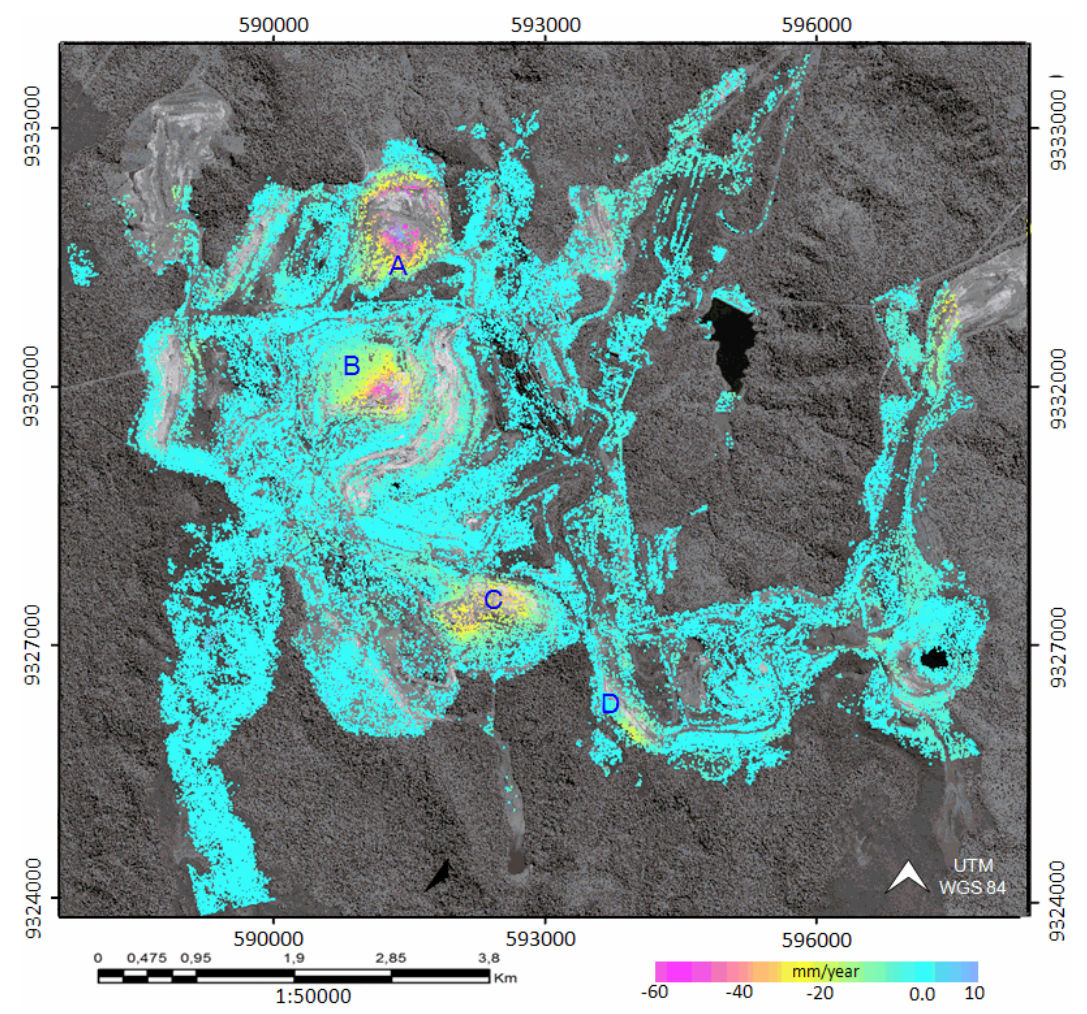

Figure 6. PSI displacement map, expressed by the average LoS velocity, using the 33 TSX-1 images on the panchromatic GeoEye image, providing a synoptic view of the deformation affecting the Carajás complex. 
Relevant ground displacement was found related to the overall stability around and within pits, waste piles and mining infrastructures (green-bluish regions, Figure 6). However, high deformation rates (yellow-reddish regions, Figure 6) with negative values corresponding to motion away from the satellite $(\mathrm{mm} / \mathrm{yr})$ were also detected over the waste piles NW-1 (letters A), W (letter B) and SIV (letter C). Furthermore, it was also possible to detect evidences of deformation over the slopes of the N5W mine (letter D). For the waste piles, the detected displacement was interpreted as related to settlements, showing values normally expected for this manmade structure. On the other hand, lithostructural and lithogeomechanical attributes have played a key role in the displacements related to cut slopes. The maximum accumulated displacements (along the LoS and away from the satellite) were $-93 \mathrm{~cm}$ (waste pile NW-1, letter A), $-68 \mathrm{~cm}$ (waste pile W, letter B), $-48 \mathrm{~cm}$ (waste pile S-IV, letter C), and $-36 \mathrm{~cm}$ (cut slopes of N5W, letter D).

A set of measurement points using total station/prisms were available for the validation. In order to make representative comparisons the vertical prism measurement data was converted to the LoS of the TSX-1 satellite. The conversion was performed by multiplying the prism measurements by the cosine of the incidence angle $\left(\theta \approx 41^{\circ}\right)$. With the purpose to ensure that the values obtained by both interferometric and prism measurement refer to the same place, it was selected only the closest data pairs. The available field data is related to six sites located in the cut slopes that lead to the mine waste pile NW-I. These slopes are constituted of highly weathered metavolcanic rocks. ${ }^{23}$ Figure 7 shows the PSI displacement map, the positions of the prism and the related displacement measurements of both techniques.
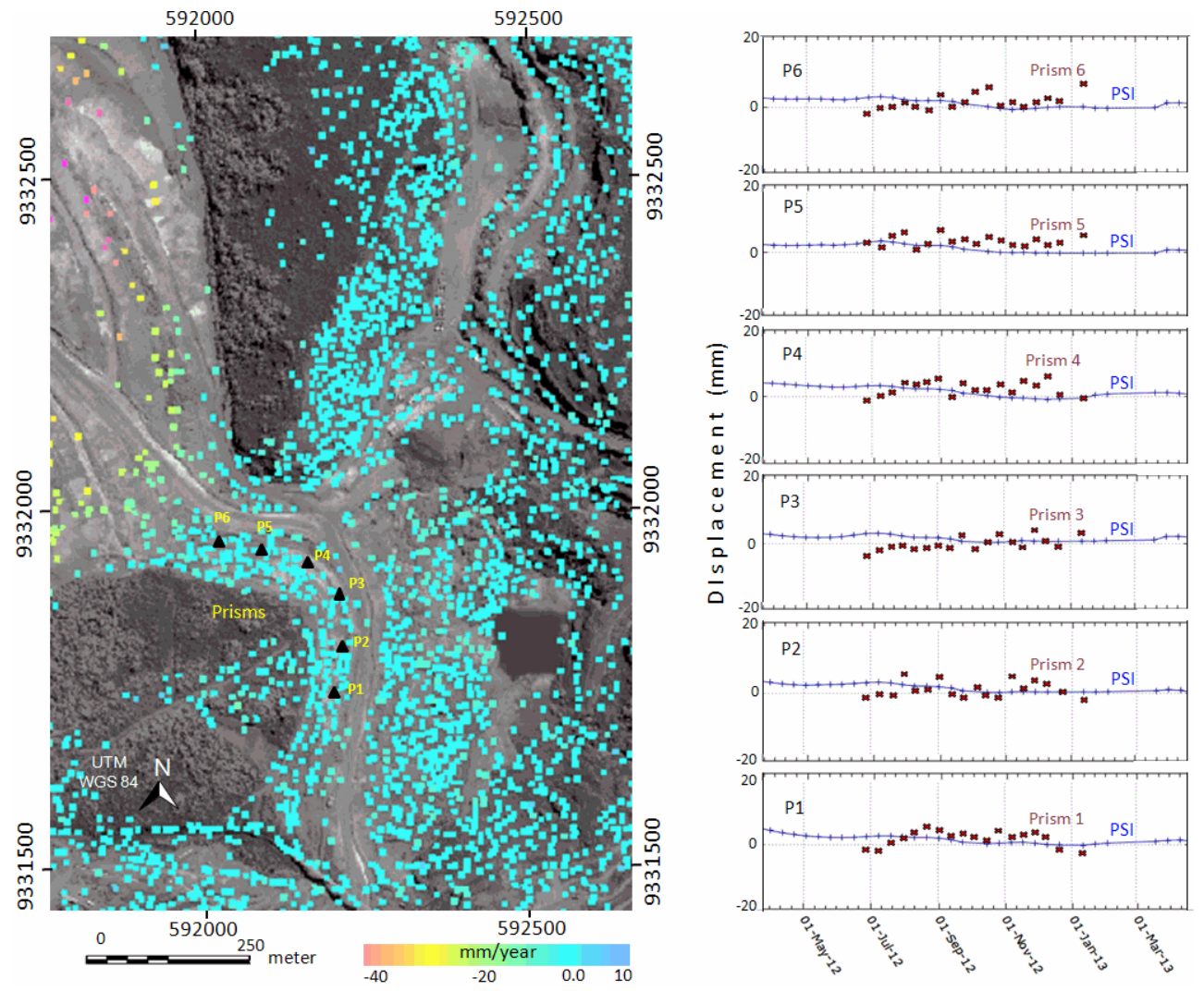

Figure 7. Ground displacement map with prim positions (on the left) and relates graphs of displacement for both techniques (on the right)

The results shown in Figure 7, despite the poor agreement between the different measurements techniques (prism measurements have a high variability probably due to the positioning of the total station at each measurement), do not show any distinguishable deformation trend, which indicates that the slope cuts were stable during the time span. This result was also confirmed by the local geotechnical team of Vale S.A. mining company. 
During the period of TSX-1 acquisitions the slopes of N5W mine was monitored with total station/prisms. It was compared the available prism measurements from April 24,2012 up to Sept 28, 2012 with PSI results (PS were selected nearby the prisms locations) at the acquisition date from May 03, 2012 up to October 04, 2012 every 11 days. The results are shown in Figure 8.
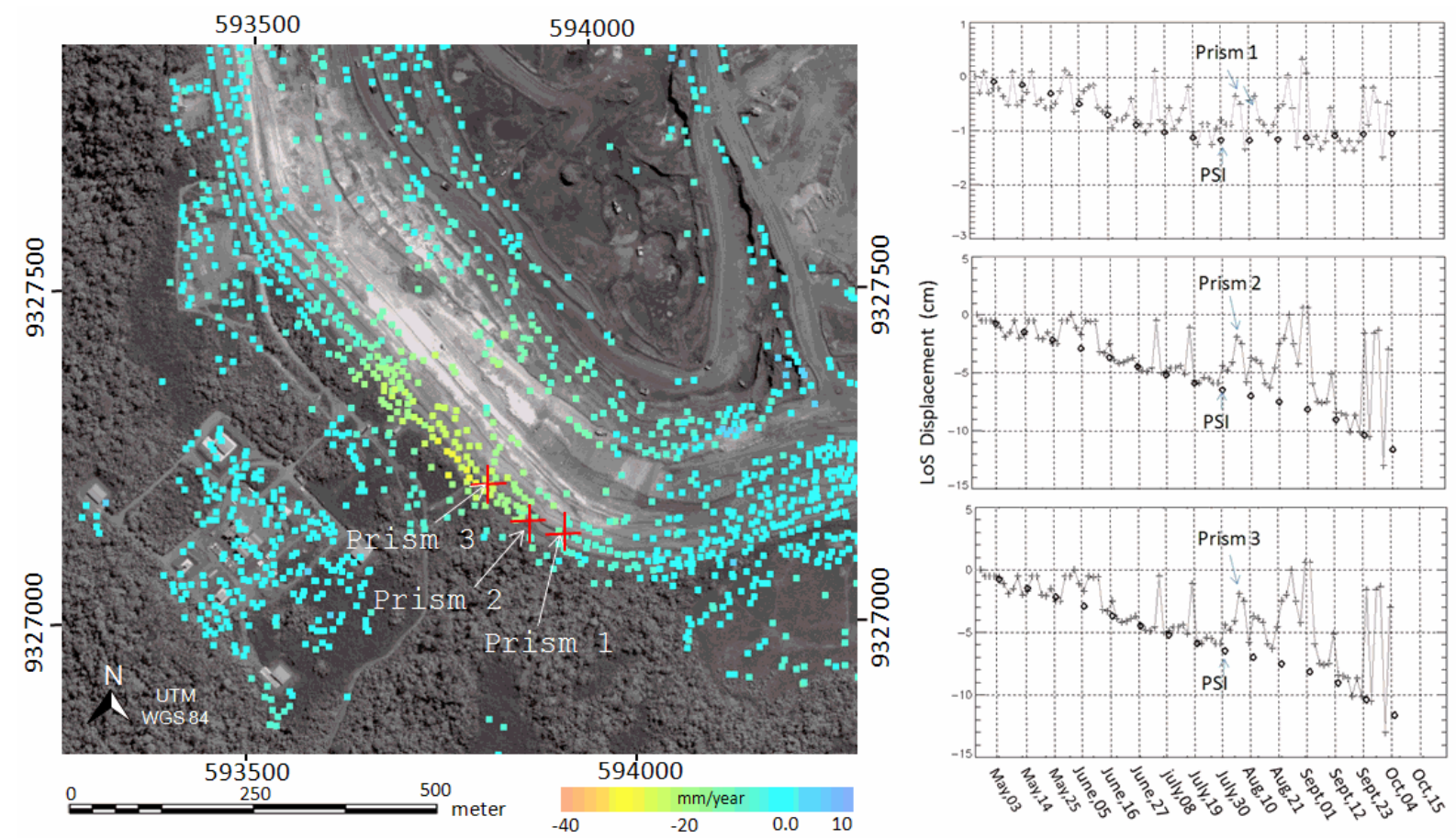

Figure 8. Ground displacement map (LoS direction) of the slopes of N5W with prism locations (on the left) obtained from March 2012 to April 2013, and the related displacement graphs (from May 03, 2012 up to October 04, 2012) for both techniques (on the right)

Figure 8 shows that the topographic measurements by total station/prisms have a high variability, probably due to the positioning of the total station at each measurement. The computed error among the PSI and prism measurements provided the following results: mean difference equal to $0.082 \mathrm{~cm}, 1.12 \mathrm{~cm}$ and $1.27 \mathrm{~cm}$ for the prism 1,2 and 3 , respectively; RMSE of $0.24 \mathrm{~cm}, 2.27 \mathrm{~cm}$ and $1.84 \mathrm{~cm}$ for the prism 1, 2 and 3, respectively. Despite these errors, there is a good agreement with PS displacement in terms of trend, for the three prism locations.

\section{CONCLUSIONS}

The combination of DTS and PSI techniques together with high-resolution TerraSAR-X data, acquired at relatively short intervals (11 day) and covering the time span from March 2012 to April 2013, allowed detecting a high rate of linear and non linear deformation on the overall mining area. The main affected sectors were the waste piles, reaching accumulated value up to $-93 \mathrm{~cm}$ on the waste pile NW-1 (Figure 1) (letter A in Figure 6). Another sector affected by ground displacement was the slopes of N5W (letter D in Figure 6) reaching accumulated value up to $-36 \mathrm{~cm}$. Deep excavations in rock masses of low geomechanical quality coupled with blasting practices and heavy precipitation contributed to this ground displacement. This work presented a methodology that can be applied to monitor linear and non linear ground displacement in large mining area providing spatial coverage and useful information about ground movement for mining planning and risk assessment. 


\section{ACKNOWLEDGEMENTS}

This investigation was carried out under the scope of a FAPESP-Vale-INPE project (Process FAPESP \# 2010/51267-9). The National Council for Scientific and Technological Development $(\mathrm{CNPq})$ is also acknowledged for a grant received by the second author during the investigation. The authors would like to thank Vale S.A. for providing access to geological and geomechanical information. Finally, the authors are particularly grateful to the Geotechnical Vale's team in Carajás for the support during the field work campaign.

\section{REFERENCES}

[1] Lundgren, P., Usai, S., Sansosti, E., Lanari, R., Tesauro, M., Fornaro, G., Berardino, P., "Modeling surface deformation observed with SAR interferometry at Campi Flegrei caldera” Journal of Geophysics Research, vol. 106, September, 19355-19367 (2001).

[2] Usai, S, "A least-squares approach for long-term monitoring of deformations with differential SAR interferometry" Proc. IGARSS 2002, vol. 2, Toronto, ON, Canada, June, 1247-1250 (2002).

[3] Schmidt , D. A. Bürgmann , R., "Time-dependent land uplift and subsidence in the Santa Clara valley, California from a large InSAR data set” J. Geophys. Res., vol. 108, no. B9, September, 2416-2429 ( 2003 ).

[4] Mora, O., Mallorquí, J.J., Broquetas, A., "Linear and nonlinear terrain deformation maps from a reduced set of interferometric SAR images" IEEE Transactions on Geosciences and Remote Sensing, 41 (10), 2243-2253 (2003).

[5] Crosetto, M., Crippa, B., Biescas, E., "Early detection and in-depth analysis of deformation phenomena by radar interferometry" Engineering Geology, 79, 81-91 (2005).

[6] Ng, A. H., Ge, L., Yan, Y., Li, X., Chang, H., Zhang, K., Rizos, C., "Mapping accumulated mine subsidence using small stack of SAR differential interferograms in the Southern coalfield of New South Wales, Australia" Engineering Geology 115, July, 1-15 (2010).

[7] Berardino, P., Fornaro, G., Lanari, R., Sansosti, E., "A new algorithm for surface deformation monitoring based on small baseline differential SAR interferograms" IEEE Trans. Geosci. Remote Sens., vol. 40, no. 11, November, 2375-2383 (2002).

[8] Lanari, R., Mora, O., Manunta, M., Mallorquí, J.J., Berardino, P., Sansosti, E., "A small-baseline approach for investigating deformations on full-resolution differential SAR interferograms" IEEE Transactions on Geosciences and Remote Sensing, 42 (7), 1377-1386 (2004).

[9] Lee, C., Lu, Z., Kwoun , O.,Won, H., "Deformation of the Augustine Volcano, Alaska, 1992-2005, measured by ERS and ENVISAT SAR interferometry” Earth Planets Space, 60, 447-452 (2008).

[10] Jiang, L., Lin. H., Ma, J., Yao, B. K., Wang, Y., "Potential of small-baseline SAR interferometry for monitoring land subsidence related to underground coal fires: Wuda (Northern China) case study" Remote Sensing of Environment 115, 257-268 (2011).

[11] Samsonov, S., D’Oreye , N., "Multidimensional time-series analysis of ground deformation from multiple InSAR data sets applied to Virunga Volcanic Province" Geophysical Journal International, 191, 1095-1108 (2012).

[12] Ferretti, A., Prati, C., Rocca, F.,"Nonlinear subsidence rate estimation using Permanent Scatterers in differential SAR interferometry" IEEE Trans. Geosci. Remote Sens. 38 (5), 2202-2212 (2000).

[13]Ferretti, A., Prati, C., Rocca, F., "Permanent scatterers in SAR interferometry" IEEE Transactions on Geoscience and Remote Sensing, 39 (1), 8-20 (2001).

[14] Werner, C., Wegmuller, U., Strozzi, T., Wiesmann, A., "Interferometric Point Target Analysis for Deformation Mapping" Proceedings of the IEEE International Geoscience and Remote Sensing Symposium (IGARSS 2003), Toulouse (France), vol. 7, 4362-4364 (2003).

[15] Hooper A, Zebker H, Segall P, Kampes B., "A new method for measuring deformation on volcanoes and other natural terrains using InSAR Persistent Scatterers" Geophysical Research Letters, 31, L23611, (2004).

[16] Paradella, W. R., Silva, M. F. F., Rosa, N. A., Kushigbor, C. A., "A geobotanical approach to the tropical rain forest environment of the Carajás Mineral Province (Amazon region, Brazil), based on digital TM-Landsat and DEM data” International Journal of Remote Sensing, 15 (8), 1633-1648 (1994).

[17] Daynes, W., “2013-Vale Brazil - Carajás Iron Ore Mine, Business Excellence, Simply ore Simply oreinspiring" <http://www.republicofmining.com/2013/01/31/vale-brazil-carajas-iron-ore-mine-by-will-daynesbusiness-excellence-january-30-2013> (01 July 2014). 
[18] Mura, J. C., Paradella, W. R.;,Gama, F. F., Silva, G. G., Galo, M., Camargo, P., Silva, A., Silva, A., Monitoring of Non Linear Ground Movement in an Open Pit Iron Mine Based on an Integration of Advanced DInSAR Techniques Using TerraSAR-X Data, Remote Sensing, 8, 409 (2016)

[19] Constantini, M., "A Novel Phase-Unwrapping Algorithm based on Network Programming" IEEE Trans. Geosci. Remote Sens., vol. 36, no. 3, May, 813-820 (1998).

[20] Werner, L. C., Wegmueller, U., Strozzi, T., "Deformation Time-series of the Lost-Hills Oil Field using a MultiBaseline Interferometric SAR Inversion Algorithm with Finite Difference Smoothing Constrains" AGU Fall Meeting, December, (2012).

[21] Mura J. C., Paradella W. R., Gama F. F., Santos A. R., Monitoring of Surface Deformation in Open Pit Mine Using DInSAR Time-Series: A Case Study in the N5W Iron Mine (Carajás, Brazil) using TerraSAR-X data. Proceedings of SPIE Remote Sensing 2014 Conferences, Vol. 9243 924311-1 (2014).

[22] Paradella W. R., Cheng, P., "Using GeoEye-1 Stereo Data in Mining Applications: Automatic DEM Generation", Geoinformatics, v. Jan-Feb, 10-12, (2013).

[23] M. E. Hartwig, W. R. Paradella, and J. C. Mura, "Detection and monitoring of surface motions in active open pit iron mine in the Amazon region; using persistent scatterer interferometry with TerraSAR-X satellite data," Remote Sensing. 5, 4719-4734 (2013). 